\title{
Nogo-66 receptor activation inhibits neurite outgrowth and increases $\beta$-amyloid protein secretion of cortical neurons
}

\author{
FEI XIAO ${ }^{1}$, LIAN-FENG LIN $^{1}$, XIN CHENG $^{1}$, QIN GAO $^{1}$ and HUAN-MIN LUO ${ }^{1,2,3}$ \\ ${ }^{1}$ Department of Pharmacology, School of Medicine, and ${ }^{2}$ Institute of Brain Science, Jinan University; \\ ${ }^{3}$ Joint Laboratory for Brain Function and Health, Jinan University and The University \\ of Hong Kong, Jinan University, Guangzhou 510632, P.R. China
}

Received September 3, 2011; Accepted November 21, 2011

DOI: $10.3892 / \mathrm{mmr} .2011 .692$

\begin{abstract}
A Nogo-A to Nogo-66 receptor (NgR) pathway is well known to contribute to the inhibition of the neurite regeneration of adult central nervous system neurons after traumatic injuries. Recent evidence suggests that Nogo-A and $\mathrm{NgR}$ are involved in the pathology of Alzheimer's disease (AD), as evidenced by the fact that Nogo-A is overexpressed by hippocampal neurons in patients with $\mathrm{AD}$ and is associated with $\beta$-amyloid protein $(\mathrm{A} \beta)$ deposits in senile plaques. In the present experiments, we investigated the potential role of Nogo-A in both neurite outgrowth and $A \beta$ generation in cortical neurons. Our results showed that activation of $\mathrm{NgR}$ not only inhibited neurite outgrowth in cortical neurons by activating the rho-associated coiled coil-containing protein kinase (ROCK) and protein kinase $\mathrm{C}$, but also promoted their $\mathrm{A} \beta$ secretion, which was at least in part activated by ROCK. These findings suggest that the overexpression of Nogo-A and the activation of $\mathrm{NgR}$ inhibit neurite outgrowth and alter neuronal metabolism, resulting in overproduction and/or release of $\mathrm{A} \beta$, which in turn may trigger the onset and development of AD. Inhibition of ROCK can promote neurite outgrowth and reduce $\mathrm{A} \beta$ production of cortical neuron, which suggests that ROCK appears to be a good target for AD therapy.
\end{abstract}

\section{Introduction}

Alzheimer's disease (AD) is a prevalent neurodegenerative disease that impairs the memory and cognition of patients. The main pathological changes are the formation of senile plaque (SP) and neurofibrillary tangle, as well as loss of neurons and synapses (1). There are many hypotheses to explain the pathogenesis of $\mathrm{AD}$ to date. According to the amyloid hypothesis, accumulation of $\beta$-amyloid protein $(\mathrm{A} \beta)$ and the formation of

Correspondence to: Dr Huan-Min Luo, Department of Pharmacology, School of Medicine, Jinan University, Guangzhou 510632, P.R. China E-mail: tlhm@jnu.edu.cn

Key words: Nogo-66 receptor, Nogo-P4, nerve regeneration, amyloid protein, Alzheimer's disease neurotoxic $A \beta$ oligomes in the brain are the primary causative factors of AD pathogenesis (2).

The Nogo-A is a protein expressed by oligodendrocytes and is a major component of myelin in the central nervous system (CNS). It impairs nerurite outgrowth in vitro and is thought to limit axonal growth in vivo after injury in adult mammalian CNS (3). Recent evidence suggests that Nogo-A and Nogo receptor $(\mathrm{NgR})$ are involved in the pathology of AD. $\mathrm{NgR}$ immunoreactivity was found to be present in more than $50 \%$ of pyramidal neurons of the hippocampus and may be related to the formation of tangles in AD (4). Both Nogo and $\mathrm{NgR}$ are mislocalized in AD brains, and interaction of amyloid precursor protein (APP) with the $\mathrm{NgR}$ reduces amyloid- $\beta$ plaque deposition (5). Nogo-A is overexpressed by hippocampal neurons in $\mathrm{AD}$ and is associated with $\mathrm{A} \beta$ deposits in $\mathrm{SP}$ as determined using immunohistochemisty (6). Although Nogo-A plays essential roles in AD pathology, there remains a need to determine its exact effect and underlying mechanism. The purpose of this study was to investigate the potential role of Nogo-A in both neurite outgrowth and $A \beta$ generation of cortical neurons. We speculated that overexpression of Nogo-A inhibits neurite outgrowth and promotes $A \beta$ secretion simultaneously, which may facilitate the onset and development of AD. To test this hypothesis, we examined the effect of $\mathrm{NgR}$ activation by Nogo-A on neurite outgrowth and $A \beta$ secretion of cortical neurons, which in turn may provide insight into potential effects and mechanisms of Nogo-A in AD pathogenesis.

\section{Materials and methods}

Materials. Nogo-P4 was purchased from Alpha Diagnostic Intl. Co. NEP1-40 was purchased from Tocris Co. Y-27632, GÖ6976 and the microtubule-associated protein 2 (MAP2) antibody were supplied by Sigma Co. Neurobasal ${ }^{\mathrm{TM}}$, a basal culture medium, and B27 supplement were from Gibco Co. The Prime Script ${ }^{\mathrm{TM}}$ RT and SYBR ${ }^{\circledR}$ Premix Ex Taq ${ }^{\mathrm{TM}}$ kits were from Takara Co. NSE monoclonal antibody and SABC immunohistochemical kit were from Boster Biotech Co. The human/rat $\beta$-amyloid (42) ELISA kit (high-sensitive) was from Wako Co. Neonatal Sprague-Dawley rats were provided by the Experimental Animal Center of Guangdong Province. All other agents used were of high grade and commercially available. 
Table I. Primer sequences of rat MAP2 and GAPDH.

\begin{tabular}{lll}
\hline Gene & Gene Bank entry & \multicolumn{1}{c}{ Primer sequence } \\
\hline MAP2 & NM_013066.1 & Sense: CAGAACAAACAGCTGCACTGGA \\
GAPDH & NM_017008 & Antisense: TCTAAAGGCTCAGCGAATGAGGA \\
& & Sense: GGCACAGTCAAGGCTGAGAATG \\
& Antisense: ATGGTGGTGAAGACGCCAGTA \\
\hline
\end{tabular}

Isolation and primary cultures of rat cerebral cortical neurons. Primary dissociated cortical neurons were prepared from 1-dayold Sprague Dawley neonatal rats, as described previously, with some modifications (7). Dissociated cells from cortical hemispheres were collected and resuspended in Neurobasal supplemented with $2 \%$ B27 at a density of $\sim 3.6 \times 10^{5}$ cells $/ \mathrm{ml}$. Medium (600 $\mu \mathrm{l} /$ well) was plated in 24-well plates. Cultures were maintained at $37^{\circ} \mathrm{C}$ in a $5 \% \mathrm{CO}_{2}$ atmosphere.

Identification of neurons. Identification of neurons was determined by staining with two neuron-specific anti-NSE and anti-MAP2 antibodies. After being cultured for 2 days, the cells were fixed for $30 \mathrm{~min}$ in $4 \%$ formaldehyde in PBS, rinsed and transferred into normal goat serum, followed by staining with primary rabbit anti-rat NSE IgG (1:200) and secondary goat anti-rabbit $\operatorname{IgG}(1: 100)$ using the SABC kit. Mouse anti-MAP2 $\operatorname{IgG}(1: 200)$ was detected with goat anti-mouse $\operatorname{IgG}(1: 100)$.

Neurite outgrowth assay. Neurite outgrowth assays were performed as described previously (8). Briefly, assays were carried out in 24-well plates after treatment with drugs for $48 \mathrm{~h}$. Random fields were photographed with an Olympus IX71 inverted research microscope. Images were captured, and quantitative analysis allowed the determination of average neurite length and the number of cells with neurites using Image-Pro Plus software (Media Cybernetics, Silver Spring, MD, USA). Four independent wells were scored for each drug tested. The number of cells bearing a process greater than a 2-cell-body diameter in length were counted as cells with neurites.

Real-time quantitative polymerase chain reaction ( $q P C R$ ) for the expression of MAP2. Firstly, the standard curves for goal gene MAP2 mRNA and housekeeping gene GAPDH mRNA were established. Total mRNA was extracted from the normal cultured neurons and used for the reverse-transcription PCR to obtain the cDNA. We prepared a 1:10 dilution series for cDNA with the result of 1, 1:10,1:100,1:1,000 and 1:10,000. The plate was subjected to the following cycling using the LightCycler 450 Detection System (Roche Diagnostics Inc., Mannheim, Germany): $95^{\circ} \mathrm{C}$ for $10 \mathrm{sec} ; 95^{\circ} \mathrm{C}$ for $5 \mathrm{sec} ; 63^{\circ} \mathrm{C}$ for $10 \mathrm{sec}$; $72^{\circ} \mathrm{C}$ for $10 \mathrm{sec}$. The expression and specificity were normalized by the assay of the melting curve. With the establishment of the standard curves for MAP2 and GAPDH, the mRNA expression levels of MAP2 in each test sample were normalized as previously described. The primer sequences used are shown in Table I.

ELISA assay for the level of $A \beta_{42}$ in the culture medium. ELISA assay for $A \beta_{42}$ level was performed using commercial kits following the manufacturer's instructions. Standard solution $(100 \mu \mathrm{l})$ and test samples were added to each well and left refrigerated overnight at $4^{\circ} \mathrm{C}$. The solutions from each well were discarded using a microplate washer, and washed five times with wash solution. HRP-conjugated antibody solution $(100 \mu \mathrm{l})$ was added to each well and left refrigerated for $1 \mathrm{~h}$ at $4^{\circ} \mathrm{C}$. Subsequently, the antibody solutions were removed from the wells and washed five times. Tetramethlybenzidine (TMB) solution $(100 \mu \mathrm{l})$ was added to each well within a short interval, thus starting the HRP reaction at room temperature in the dark for $45 \mathrm{~min}$. Stop solution $(100 \mu \mathrm{l})$ was added to each well in order to terminate the reaction. Color development in each well was detected using a microplate reader (Bio-Rad Inc., Foster City, CA, USA) at $450 \mathrm{~nm}$ within 30 min.

Statistical analysis. Results are presented as the means \pm SD. Comparisons between groups were made by ANOVA. Analyses were performed using SPSS 11.0 statistical software (SPSS Inc., Chicago, IL, USA). A P-value $<0.05$ was considered to denote statistical significance.

\section{Results}

Culture and identification of rat cortical neurons. Most cells completely attached to the matrix after $6 \mathrm{~h}$ of plating in cultures. A few cells began to extend 1-2 short neurites (Fig. 1A). When continually grown for $48 \mathrm{~h}$ in vitro, the cell bodies enlarged and appeared to be surrounded by a light halo, and the number and length of neurites increased markedly (Fig. 1B). More than $90 \%$ of the cells were NSE-immunoreactive (Fig. 1C) and MAP2-immunoreactive (Fig. 1D), suggesting that the majority of the cultured cells were neurons.

Activation of $\mathrm{NgR}$ inhibits neurite outgrowth and increases $A \beta_{42}$ secretion in cortical neurons. It was reported (9) that Nogo-P4 is the active fragment of Nogo-66 and activates the $\mathrm{NgR}$. Cultured cortical neurons were treated with Nogo-P4 at different concentrations (3.5, 7 and $14 \mu \mathrm{M})$ in Neurobasal at $37^{\circ} \mathrm{C}$ for 2 days to observe its effects on neurite outgrowth and levels of MAP2 mRNA and A $\beta_{42}$.

The 3-(4, 5-dimethylthiazol-2-yl)-2, 5-diphenyl-tetrazolium bromide (MTT) assay demonstrated that Nogo-P4 at different concentrations did not have a toxic effect on cortical neuron survival (data not shown). Treatment of the cortical neurons with different concentrations of Nogo-P4 (7 and $14 \mu \mathrm{M})$ significantly decreased the number of cells with neurites compared to the number in the PBS-treated control (Fig. 2E). Nogo-P4 at different concentrations (3.5, 7 and 

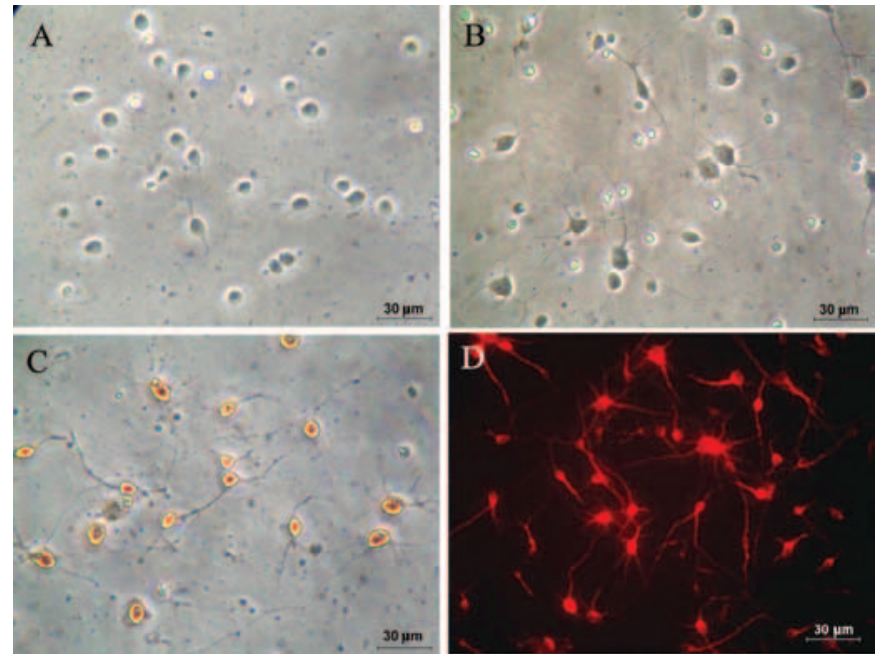

Figure 1. Culture and identification of rat cortical neurons. (A) Adhesion of the cells after $6 \mathrm{~h}$. (B) Neurons cultured for $48 \mathrm{~h}$ after adhesion. (C) Cells with NSE immunochemical staining. (D) Cells with MAP2 immunochemical staining. Bar, $30 \mu \mathrm{m}$.

$14 \mu \mathrm{M})$ significantly decreased the average neurite length in a dose-dependent manner (Fig. 2F).

qPCR was applied to analyze the effect of Nogo-P4 on MAP2 mRNA expression after the cell morphology was photographed. Firstly, the standard curves for MAP2 mRNA and GAPDH mRNA were established (Fig. 2G and $\mathrm{H}$ ). The mRNA expression levels of MAP2 in each test sample were then normalized as previously described. In the groups treated with different concentration of Nogo-P4 (3.5, 7 and $14 \mu \mathrm{M})$, MAP2 mRNA expression was decreased compared to that in the PBS-treated controls (Fig. 3I), which was consistent with the neurite outgrowth assay.

The culture medium was obtained to assay the content of $\mathrm{A} \beta_{42}$ according to the instructions of the ELISA kit after the cell morphology was observed. Nogo-P4 at different concentrations (7 and $14 \mu \mathrm{M})$ significantly increased the production of $\mathrm{A} \beta_{42}$ by 23.71 and $30.87 \%$, respectively (Fig. 3J).

Effects of NEP1-40 on neurite outgrowth and $A \beta_{42}$ secretion. First, we studied the role of $\mathrm{NgR}$ in the inhibition of neurite outgrowth and increase in $\mathrm{A} \beta_{42}$ secretion induced by Nogo-P4. The cortical neurons were treated with the NgR antagonist, NEP1-40 (1, 2 and $4 \mu \mathrm{M})$, in the presence or absence of Nogo-P4 for 2 days.

As shown in Fig. 3, different concentrations of NEP1-40 had no effect on the neurite outgrowth of cortical neurons compared to that in the PBS-treated controls. Treatment of rat cortical neurons with Nogo-P4 significantly decreased the number of cells with neurites and the average neurite length compared to such values in the PBS-treated control. However, treatment with NEP1-40 (2 and $4 \mu \mathrm{M}), 15$ min prior to Nogo$\mathrm{P} 4$, significantly increased the number of cells with neurites and the average neurite length compared to both values in the Nogo-P4-treated alone group.

The MAP2 mRNA expression was not affected by NEP1-40 compared to the PBS-treated controls. In the Nogo-P4-treated group, the MAP2 mRNA expression was decreased. Different concentrations of NEP1-40 $(1,2$ and $4 \mu \mathrm{M})$ increased the
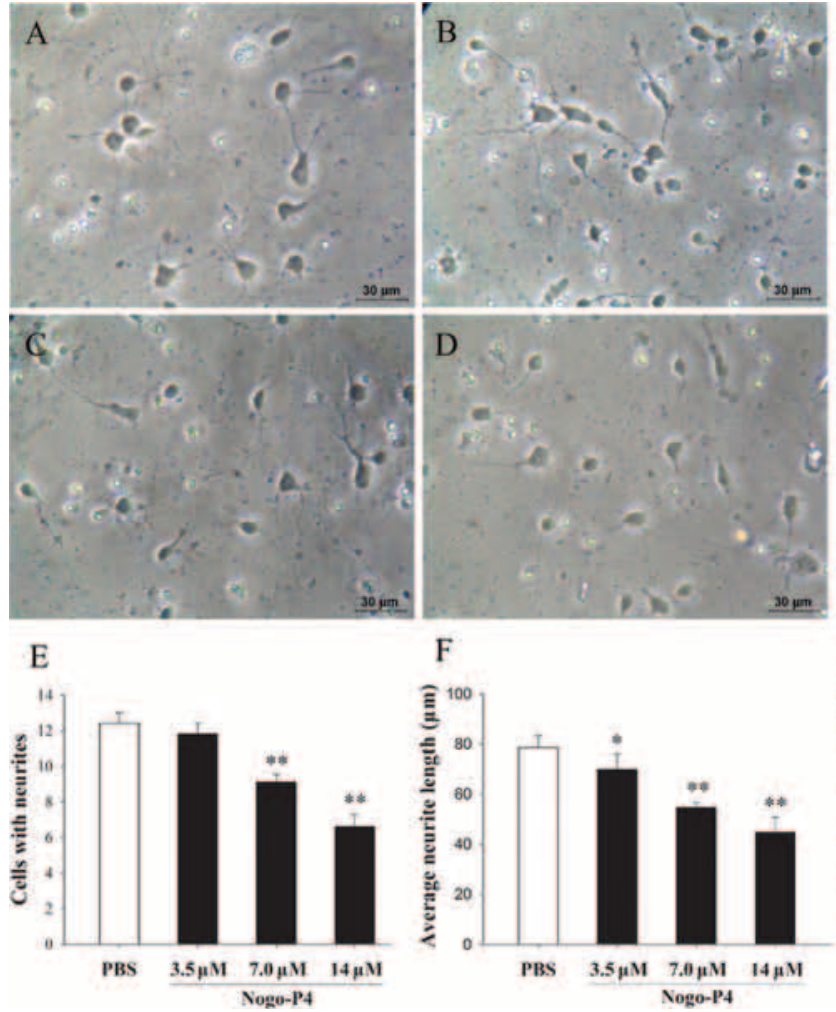
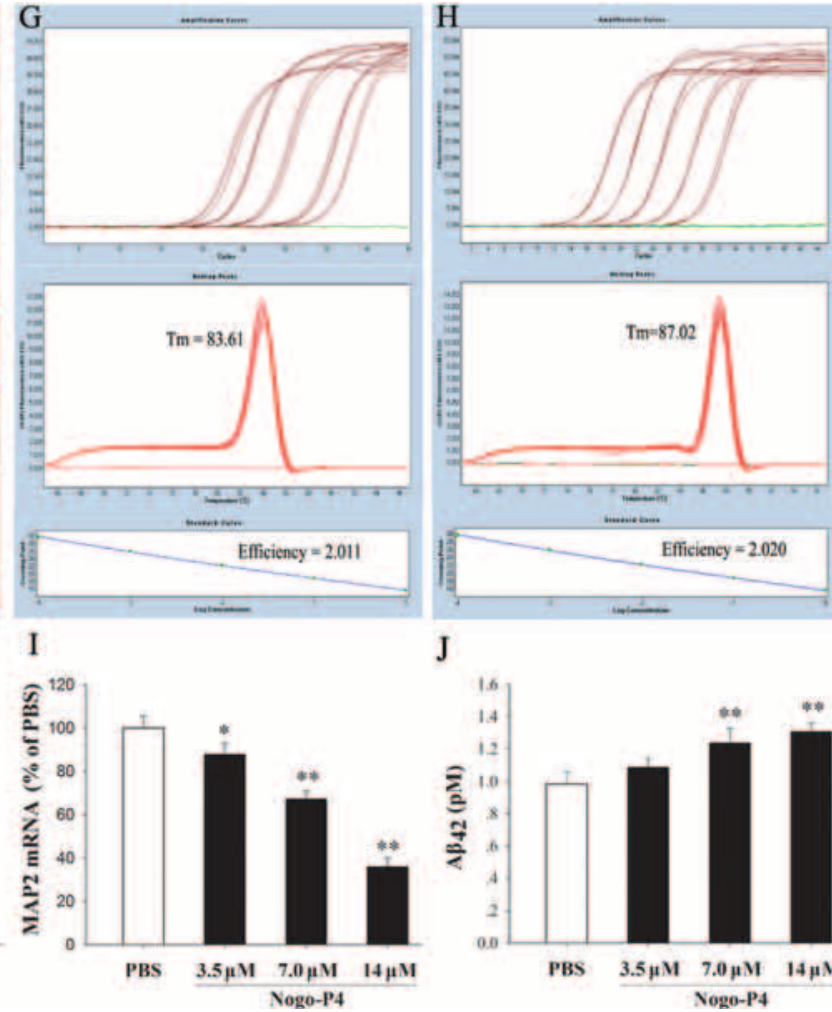

Figure 2. Nogo-P4 inhibited the neurite outgrowth and increased A $\beta_{42}$ secretion in cortical neurons. (A) PBS. (B) Nogo-P4 (3.5 $\left.\mu \mathrm{M}\right)$. (C) Nogo-P4 (7 $\left.\mu \mathrm{M}\right)$. (D) Nogo-P4 $(14 \mu \mathrm{M})$. (E) Nogo-P4 reduced the number of cells with neurites. (F) Nogo-P4 reduced the average length of neurites. (G and H) qPCR standard curves of MAP2 and GAPDH. (I) Nogo-P4 down-regulated the expression of MAP2 mRNA. (J) Nogo-P4 increased A $\beta_{42}$ secretion in cortical neurons. All data represent the means $\pm \mathrm{SD}(\mathrm{n}=4)$. ${ }^{*} \mathrm{p}<0.05$ vs. the PBS group; ${ }^{* *} \mathrm{p}<0.01$ vs. the PBS group. 

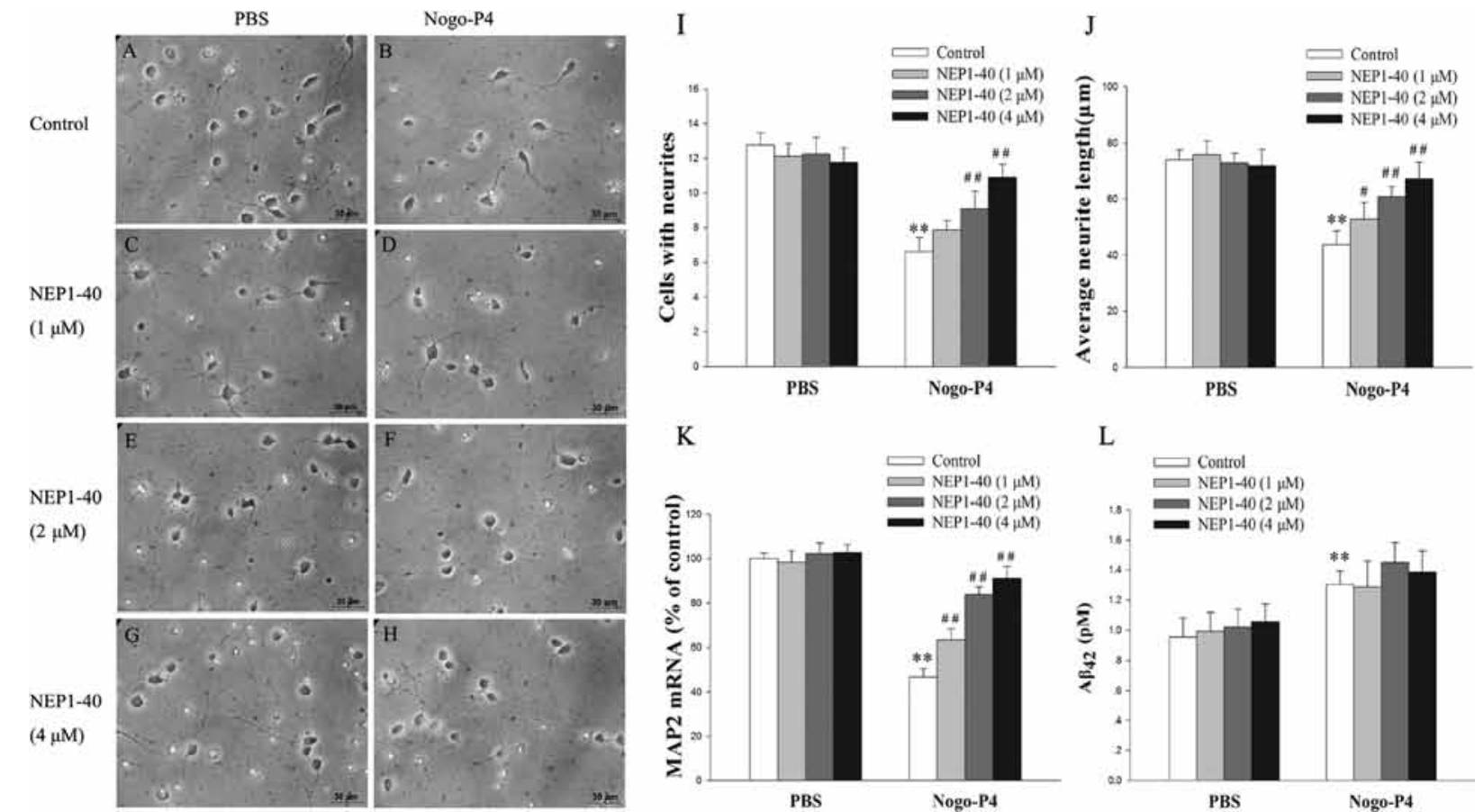

Figure 3. Effects of NEP1-40 on neurite outgrowth and A $\beta_{42}$ secretion. (A-J) NEP1-40 overcame the neurite outgrowth inhibition of Nogo-P4. (K) NEP1-40 overcame the MAP2 mRNA inhibition of Nogo-P4. (L) NEP1-40 did not change the A $\beta_{42}$ secretion induced by Nogo-P4. All data represent the means \pm SD $(\mathrm{n}=4) .{ }^{* *} \mathrm{p}<0.01$ vs. the PBS control group; ${ }^{*} \mathrm{p}<0.05$ vs. the Nogo-P4-treated group; ${ }^{\# \#} \mathrm{p}<0.01$ vs. the Nogo-P4-treated group.
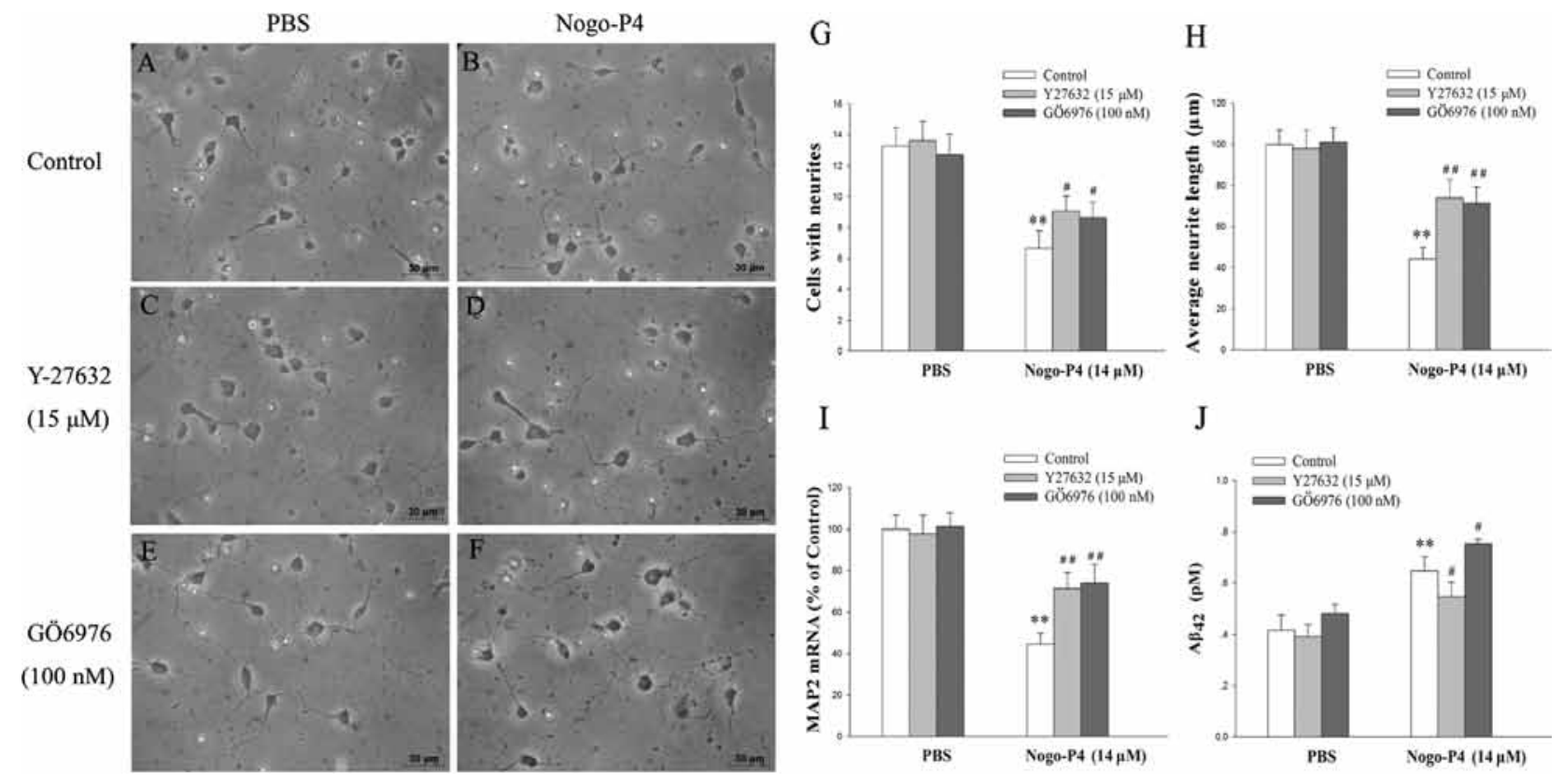

Figure 4. Effects of Y-27632 and GÖ6976 on neurite outgrowth and $A \beta_{42}$ secretion. (A-H) Y-27632 and GÖ6976 overcame the neurite outgrowth inhibition of Nogo-P4. (I) Y-27632 and GÖ6976 overcame the MAP2 mRNA expression against Nogo-P4. (J) Y-27632 reduced the A $\beta_{42}$ secretion against Nogo-P4, but not GÖ6976. All data represent the means $\pm \mathrm{SD}(\mathrm{n}=4)$. ${ }^{* *} \mathrm{p}<0.01$ vs. the PBS control group; ${ }^{*} \mathrm{p}<0.05$ vs. the Nogo-P4-treated group. ${ }^{\#} \mathrm{p}<0.01$ vs. the Nogo-P4-treated group.

MAP2 mRNA expression compared to the Nogo-P4-treated group in a dose-dependent manner (Fig. 3K).

There was no effect after treatment with the different concentrations of NEP1-40 $(1,2$ and $4 \mu \mathrm{M})$ on the $\mathrm{A} \beta_{42}$ level in the untreated control. Different concentrations of NEP1-40 did not decrease the $A \beta_{42}$ level compared to the level in the Nogo-P4-treated group (Fig. 3L).
Effects of Y-27632 and GÖ6976 on neurite outgrowth and $A \beta_{42}$ secretion. We next evaluated the role of rho-associated coiled coil-containing protein kinase (ROCK) and protein kinase $\mathrm{C}$ (PKC) on the inhibition of neurite outgrowth and the increase in $A \beta_{42}$ secretion induced by Nogo-P4. The ROCK inhibitor Y-27632 and the PKC inhibitor GÖ6976 were utilized in the experiment. The concentrations of Y-27632 
(15 $\mu \mathrm{M})$ and GÖ6976 (100 $\mathrm{nM})$ were referred to in previous studies $(10,11)$.

As illustrated in Fig. 4, Y-27632 and GÖ6976 had no effect on the neurite outgrowth of cortical neurons compared to untreated controls. Treatment of rat cortical neurons with Nogo-P4 significantly decreased the number of cells with neurites and the average neurite length compared to such values in the untreated control. However, treatment with Y-27632 and GÖ6976, 15 min prior to Nogo-P4, significantly increased the number of cells with neurites and the average neurite length compared to Nogo-P4 alone-treated neurons.

Compared to that of the PBS control group, Y-27632 and GÖ6976 did not affect the mRNA expression of MAP2 in the group of untreated neurons, while the mRNA expression of MAP2 was decreased significantly in the Nogo-P4 group. Y-27632 and GÖ6976 increased the mRNA expression of MAP2 in the group of neurons treated with Nogo-P4 (Fig. 4I).

Y-27632 and GÖ6976 had no effect on $A \beta_{42}$ secretion in the untreated control. Nogo-P4 increased $A \beta_{42}$ secretion in cortical neurons. Compared to that of the Nogo-P4-treated neurons, the $A \beta_{42}$ level was decreased in the group of neurons treated with Nogo-P4 and Y-27632, while the $A \beta_{42}$ level was increased in the group of neurons treated with Nogo-P4 and GÖ6976 (Fig. 4J).

\section{Discussion}

Nogo-P4, the 31-55 amino acid of the Nogo-66 peptide, is sufficient to produce core inhibitory properties of neurite growth (9). Nogo-66 in vitro was found to exhibit neurite outgrowth inhibition in a variety of nerve cells, such as dorsal root ganglion cells $(9,12), \mathrm{PC} 12$ (9) and cerebellar granule cells (11). The mechanism of the inhibition of neurite growth by Nogo-66 in nerve cells is not completely clear. The main signal transduction process involves binding of Nogo-66 to NgR on nerve cell membranes, activation of two downstream signaling molecules, ROCK and PKC, and subsequent exertion of neurite growth inhibition effect (13). The effect of Nogo-66 on the neurite growth of cortical neurons and its mechanisms have not been reported. Our results of the neurite outgrowth assay revealed that different concentrations of Nogo-P4 inhibited the neurite outgrowth of cortical neurons in a dose-dependent manner. MAP2 is an important regulator of the assembly of microtubules and induces neurite outgrowth. The expression of MAP2 reflects the level of neurite growth $(14,15)$. A significant down-regulation of MAP2 mRNA was observed in cortical neurons treated with Nogo-P4 compared to the control, which indicates that Nogo-P4 impairs neurite outgrowth. These data are, therefore, consistent with the morphological evidence that Nogo-P4 has an inhibitory effect on neurite outgrowth.

The potential mechanism of the inhibition of neurite outgrowth by Nogo-P4 has been explored. The outgrowthinhibiting activity of Nogo-P4 was attenuated after cells were incubated with the NgR antagonist NEP1-40. Similar results were obtained after inhibition of PKC and ROCK by GÖ6976 and Y-27632, respectively. Furthermore, qPCR results showed that NEP1-40, inhibition of PKC and ROCK also increased MAP2 gene expression decreased by Nogo-P4, which was consistent with the morphological observation. Taken together, these results indicate that Nogo-P4 inhibits neurite outgrowth by activation of $\mathrm{NgR}, \mathrm{ROCK}$ and PKC.

APP processing is routinely described as occurring mainly via two alternative pathways. The amyloidogenic and non-amyloidogenic pathways would therefore be the result of APP cleavage, first either by $\beta$-secretase (amyloidogenic pathway) or by $\alpha$-secretase (non-amyloidogenic pathway), followed by the release of the toxic $\mathrm{A} \beta$ peptide or non-toxic $\mathrm{P} 3$ peptide, respectively, by the action of $\gamma$-secretase. The highly amyloidogenic 42-residue $A \beta$ peptide $\left(A \beta_{42}\right)$ is more prone to aggregate and is considered to be more neurotoxic than the shorter $A \beta$ species (16). In recent years, several classes of molecules with a modulatory function in APP processing and $\mathrm{A} \beta$ secretion have been identified. These include the neuronal Munc-18 interacting proteins (Mints)/X11s, members of the reticulon family (RTN-3 and RTN4-B/C) and NgR (17). NgR interacts with APP to reduce the production of $A \beta$ (5), while RTN-3 and RTN4-B/C interact with $\beta$-secretase and inhibit the production of $A \beta$ (18). However, the potential effects of Nogo-A and/or Nogo-66 in mediating APP metabolism have not yet been reported. Results from the present study have provided strong evidence that the Nogo-66 active fragment Nogo-P4 regulates APP processing and promotes $A \beta_{42}$ secretion of cortical neurons.

In an attempt to elucidate the molecular basis for Nogo-P4induced $\mathrm{A} \beta_{42}$ secretion, a receptor and kinase blockers, such as NEP1-40, Y27632 and GÖ6976, were used to treat cortical neurons in the presence or absence of Nogo-P4. Our results showed that different concentrations of NEP1-40 had no effect on Nogo-P4-induced $\mathrm{A} \beta_{42}$ secretion in cultured cortical neurons. This indicates that the effect of Nogo-P4 on $\mathrm{A} \beta_{42}$ secretion is mediated by other non-NgR pathways, an issue that remains to be resolved by further investigation.

Our results also showed that ROCK inhibitor Y-27632 inhibited Nogo-P4-stimulated $A \beta_{42}$ secretion. This indicates that $\mathrm{Y}-27632$ reduces $A \beta_{42}$ by inhibiting the activation of ROCK, and Nogo-P4 increases $A \beta_{42}$ secretion by activating the ROCK pathway. Previous studies have shown that a subset of non-steroidal anti-inflammatory drugs (NSAIDs) lower the level of $A \beta_{42}$ through inhibition of Rho activity in SY5Y APP cells (19). The constitutively active ROCK1 molecule was found to inhibit statin-stimulated SAPP $\alpha$ shedding in cultured APP transfected cells (20). We infer that activation of ROCK reduces non-amyloidogenic sAPP $\alpha$ secretion, which may facilitate amyloidogenic metabolism of APP resulting in an increase in $\mathrm{A} \beta_{42}$ secretion.

The PKC inhibitor GÖ6976 did not reduce the $A \beta_{42}$ secretion caused by Nogo-P4, but instead increased $A \beta_{42}$ secretion. This study indicated that the combination of Nogo-P4 and $\mathrm{NgR}$, activated the PKC which reduced the secretion of $\mathrm{A} \beta_{42}$, while the PKC inhibitor increased its secretion. It was reported (21) that the increase in SAPP $\alpha$ secretion by deprenyl was blocked by the PKC inhibitor GF109203X and staurosporine. Since the sAPP $\alpha$ is generated through the APP non-amyloidogenic pathway, we hypothesized that activation of $\mathrm{PKC}$ results in APP through the non-amyloidogenic pathway, and then reduces APP through the amyloidogenic pathway, thus indirectly reducing the secretion of $A \beta_{42}$.

Taken together, our results demonstrated that activation of $\mathrm{NgR}$ by Nogo-P4 regulates the secretion of $\mathrm{A} \beta_{42}$ through at 
least two downstream signaling molecules, ROCK and PKC. Activation of ROCK may increase $A \beta_{42}$ and activation of PKC may decrease $A \beta_{42}$. Therefore, their combined treatment would result in having no effects on $A \beta_{42}$, which is consistent with the results that the $\mathrm{NgR}$ antagonist had no effect on $\mathrm{A} \beta_{42}$, despite the level of $A \beta_{42}$ being indeed increased after treatment with Nogo-P4. This suggests that the effect of Nogo-P4 in increasing the secretion of $\mathrm{A} \beta_{42}$ may be mediated via other signaling pathways, apart from the ROCK pathway.

In summary, although Nogo-A/Nogo-66 play a role in AD pathology, their effects and mechanisms are not as yet clear. Our study found that Nogo-P4, the Nogo-66 active fragment, inhibited neurite outgrowth, yet increased the $A \beta_{42}$ level in cortical neurons, which resulted in the accumulation of neurotoxic $A \beta_{42}$ and further impaired neurite outgrowth. This may be a precipitating factor causing the onset and development of AD. From the viewpoint of a drug therapy target, NgR may be considered as a target for promoting neurite outgrowth or axon regeneration, but not as a target for the inhibition of $\mathrm{A} \beta_{42}$ generation. Similarly, PKC may be used as a target for promoting neurite outgrowth, while it also promotes $A \beta_{42}$ generation and therefore is not appropriate to use as a target for AD therapy. By contrast, ROCK appears to be a therapy target for promoting neurite outgrowth and inhibiting $A \beta_{42}$ production. Targeting ROCK may prove potentially useful and effective for the treatment of patients with AD.

\section{Acknowledgements}

This study was supported by the Natural Science Foundation of China (no. 30672450), Guangdong Province (no. S2011040002140), and the Jinan University Foundation (no. 21611336). The study was also supported by the National Key Basic Research program of China (973 Program) (no. 2011CB707500). The authors are grateful to Wen Weng and Hong-Mei Tang for the technical assistance.

\section{References}

1. Selkoe DJ: Alzheimer's disease is a synaptic failure. Science 298: 789-791, 2002.

2. Hardy J and Selkoe DJ: The amyloid hypothesis of Alzheimer's disease: progress and problems on the road to therapeutics. Science 297: 353-356, 2002.

3. Huebner EA and Strittmatter SM: Axon regeneration in the peripheral and central nervous systems. Results Probl Cell Differ 48: 339-351, 2009.
4. Zhu HY, Guo HF, Hou HL, et al: Increased expression of the Nogo receptor in the hippocampus and its relation to the neuropathology in Alzheimer's disease. Hum Pathol 38: 426-434, 2007.

5. Park JH, Gimbel DA, GrandPre T, et al: Alzheimer precursor protein interaction with the Nogo-66 receptor reduces amyloidbeta plaque deposition. J Neurosci 26: 1386-1395, 2006.

6. Gil V, Nicolas O, Mingorance A, et al: Nogo-A expression in the human hippocampus in normal aging and in Alzheimer disease. J Neuropathol Exper Neurol 65: 433-444, 2006.

7. Brewer GJ, Torricelli JR, Evege EK, et al: Optimized survival of hippocampal neurons in B27-supplemented Neurobasal, a new serum-free medium combination. J Neurosci Res 35: 567-576, 1993.

8. Mitchell PJ, Hanson JC, Quets-Nguyen AT et al: A quantitative method for analysis of in vitro neurite outgrowth. J Neurosci Methods 164: 350-362, 2007.

9. GrandPre T, Nakamura F, Vartanian T, et al: Identification of the Nogo inhibitor of axon regeneration as a Reticulon protein. Nature 403: 439-444, 2000.

10. Sivasankaran R, Pei J, Wang KC, et al: PKC mediates inhibitory effects of myelin and chondroitin sulfate proteoglycans on axonal regeneration. Nature Neurosci 7: 261-268, 2004.

11. Niederost B, Oertle T, Fritsche J, et al: Nogo-A and myelinassociated glycoprotein mediate neurite growth inhibition by antagonistic regulation of RhoA and Rac1. J Neurosci 22: 10368-10376, 2002 .

12. Chen MS, Huber AB, van der Haar ME, et al: Nogo-A is a myelin-associated neurite outgrowth inhibitor and an antigen for monoclonal antibody IN-1. Nature 403: 434-439, 2000.

13. Yiu $\mathrm{G}$ and $\mathrm{He} \mathrm{ZG}$ : Glial inhibition of $\mathrm{CNS}$ axon regeneration. Nat Rev Neurosci 7: 617-627, 2006.

14. Fukumitsu H, Ohashi A, Nitta A, et al: BDNF and NT-3 modulate expression and threonine phosphorylation of microtubuleassociated protein 2 analogues, and alter their distribution in the developing rat cerebral cortex. Neurosci Lett 238: 107-110, 1997.

15. Moreno-Flores MT, Martin-Aparicio E, Avila J, et al: Ephrin-B1 promotes dendrite outgrowth on cerebellar granule neurons. Mol Cell Neurosci 20: 429-446, 2002.

16. Querfurth HW and LaFerla FM: Mechanisms of disease Alzheimer's disease. New Engl J Med 362: 329-344, 2010.

17. Tang BL and Liou YC: Novel modulators of amyloid-beta precursor protein processing. J Neurochem 100: 314-323, 2007.

18. Murayama KS, Kametani F, Saito S, et al: Reticulons RTN3 and RTN4-B/C interact with BACE1 and inhibit its ability to produce amyloid beta-protein. Eur J Neurosci 24: 1237-1244, 2006.

19. Zhou Y, Su Y, Li BL, et al: Nonsteroidal anti-inflammatory drugs can lower amyloidogenic A beta(42) by inhibiting Rho. Science 302: 1215-1217, 2003.

20. Pedrini S, Carter TL, Prendergast G, et al: Modulation of statinactivated shedding of Alzheimer APP ectodomain by ROCK. PLoS Med 2: 69-78, 2005.

21. Yang HQ, Ba MW, Ren RJ, et al: Mitogen activated protein kinase and protein kinase $\mathrm{C}$ activation mediate promotion of sAPPalpha secretion by deprenyl. Neurochem Int 50: 74-82, 2007. 